\title{
PENGARUH MASSAGE METODE EFLURASI TERHADAP PENURUNAN INTENSITAS NYERI DISMENOREA
}

\author{
Iit Ermawati \\ Program Studi DIII Kebidanan, Stikes Hafshawaty Pesantren Zainul Hasan, Probolinggo, Indonesia \\ email: iit.ermawati83@gmail.com
}

\begin{abstract}
Abstrak
Di Indonesia angka kejadian dismenorea tipe primer adalah 54,89\%. Tujuan penelitian ini adalah untuk mempelajari pengaruh metode massage eflurasi terhadap penurunan intensitas nyeri dismenorea pada mahasiswa Prodi DIII Kebidanan STIKES Hafshawaty Pesantren Zainul Hasan Probolinggo. Metode penelitian ini menggunakan pra eksperimental (one group pre test-post test design) dengan variabel independen penelitian adalah pemberian terapi massage eflure dan variabel dependen penelitian ini adalah intensitas nyeri. yang dilakukan pengukuran dari satu kelompok subjek (pretest), subjek diberi perlakuan untuk jangka waktu tertentu dan dilakukan pengukuran kedua (post test). Selanjutnya, hasil pengukuran pretest dibandingkan dengan hasil pengukuran post test. Populasi penelitian ini adalah semua mahasiswa yang mengalami nyeri dismenorea sebesar 30 orang. Teknik sampling yang digunakan total sampling, sehingga sampel dalam penelitian ini sebesar 30 orang. Hasil penelitian menginformasikan bahwa sebagian besar responden mempunyai intensitas nyeri dismenorea sedang dan ada pengaruh penurunan intensitas nyeri dismenorea setelah dilakukan massage eflurasi. Metode yang dapat digunakan untuk mengurangi intensitas nyeri secara alami yaitu dengan melakukan massage eflurasi pada area yang tepat.
\end{abstract}

Kata kunci: massage eflurasi, penurunan, nyeri dismenorea

\begin{abstract}
In Indonesia the incidence of primary type dysmenorrhea is $54.89 \%$. The purpose of this research is to study the influence of the effleurage massage method on the decrease in the intensity of dysmenorrhea pain in students of STIKES Hafshawaty Pesantren Zainul Hasan Probolinggo. The research method used pre experimental (one group pre test-post test design) with the independent variable of research is giving effleurage massage therapy and the dependent variable is the intensity of pain which a measurement taken from one subject group (pretest), the subject was treated for a certain period of time and continued to take a second measurement (post test). Then, pretest measurement results were compared to the posttest results. The population of this study was all students who experienced dysmenorrhoea pain of 30 people. Sampling techniques are used total sampling so the sample was 30 students. The results of the study informed that most respondents had moderate intensity of dysmenorrhea pain and there was an effect of decreasing the intensity of dysmenorrhea pain after the effleurage massage. The method that can be used to reduce the intensity of pain naturally by performing effleurage massage in the right area.
\end{abstract}

Keywords: effleurage massage, decrease, dysmenorrhea pain

\section{PENDAHULUAN}

Gangguan nyeri menstruasi atau dismenorea adalah masalah yang sering dialami oleh remaja (Kusmiran, 2011). Menstruasi diartikan sebagai perdarahan secara periodik dan siklik yang berasal dari rahim disertai dengan melepasnya lapisan endometrium yang nekrosis (Prawirohardjo, 2011). Dismenorea bisa terjadi karena ketidakseimbangan hormon progesterone dalam darah sehingga menimbulkan nyeri yang terjadi pada wanita (Prayitno S, 2014). Nyeri menstruasi sangat mengganggu dalam proses belajar mengajar, yang menyebabkan sulitnya remaja putri untuk konsentrasi karena perasaan tidak nyaman yang dirasakan pada saat menstruasi, sehingga dismenorea harus ditangani agar tidak terjadi dampak yang lebih buruk bagi remaja (Nirwana AB, 2011). 
Di Indonesia angka kejadian dismenorea tipe primer adalah $54,89 \%$ sedangkan sisanya penderita dengan dismenorea sekunder. Dismenorea terjadi pada remaja dengan prevalensi berkisar antara $43 \%$ hingga $93 \%$, dimana sekitar $74-80 \%$ remaja mengalami dismenorea ringan, angka kejadian endometriosis pada remaja dengan nyeri panggul diperkirakan 25-38\%, sedangkan pada remaja yang tidak memberikan respon positif terhadap penanganan untuk nyeri haid, endometriosis ditemukan pada $67 \%$ kasus dilaparoskopi (Hestiantoro A, 2012).

Nyeri dapat diatasi dengan berbagai cara, ada yang menggunakan cara farmakologis ada juga yang menggunakan cara non farmakologis. Secara farmakologis bisa diatasi menggunakan obatobatan analgesik, sedangkan secara non farmakologis nyeri tersebut bisa diatasi dengan cara kompres panas dan dingin, stimulasi saraf elektris transkutan, distraksi, relaksasi, imajinasi terbimbing, hipnosis, akupuntur, umpan balik biologis, dan massage eflurasi (Trisnowiyoto, 2012).

Massage fflurasi akan mengurangi hipoksia pada jaringan sehingga terjadi peningkatan kadar oksigen di jaringan dan menyebabkan nyeri berkurang. Pemberian terapi massage eflurasi juga dapat menyebabkan terjadinya pelepasan hormon endorfin sehingga ambang nyeri meningkat (Apay et al., 2012).

Studi pendahuluan yang dilakukan kepada 53 mahasiswa (remaja putri) Program Studi DIII Kebidanan STIKes Hafshawaty Pesantren Zainul Hasan Probolinggo diperoleh data sebagai berikut: 64\% mahasiswa remaja putri Prodi DIII Kebidanan mengalami dismenorea dan $36 \%$ mahasiswa remaja putri tidak mengalami dismenorea.

Metode sederhana yang dapat digunakan untuk mengurangi intensitas nyeri secara alami yaitu dengan melakukan massage pada area yang tepat. Massage adalah alternatif pilihan yang tepat, alamiah dan sederhana yang dengan cepat dapat mengurangi rasa nyeri selain memakai obatobatan. Massage punggung dengan kedua tangan, dan melakukan gerakan ke atas berguna untuk membantu aliran balik vena.

Mekanisme penghambatan nyeri dengan teknik eflurasi berdasarkan pada konsep Gate Control Theory. Berdasarkan teori tersebut stimulasi serabut taktil kulit dapat menghambat sinyal nyeri dari area tubuh yang sama atau area lainnya. Stimulasi taktil dengan teknik massage eflurasi menghasilkan pesan yang sebaliknya dikirim lewat serabut saraf yang lebih besar
(Serabut A Delta). Serabut A Delta akan menutup gerbang sehingga Cortex Cerebri tidak menerima pesan nyeri karena sudah diblokir oleh Counter stimulasi dengan teknik massage eflurasi sehingga persepsi nyeri berubah, karena serabut di permukaan kulit (Cutaneus) sebagian besar adalah serabut saraf yang berdiameter luas. Teknik ini juga memfasilitasi distraksi dan menurunkan transmisi sensorik stimulasi dari dinding abdomen sehingga mengurangi ketidaknyamanan pada area yang sakit. Sebagai teknik relaksasi, massage eflurasi mengurangi ketegangan otot dan meningkatkan sirkulasi area yang sakit serta mencegah terjadinya hipoksia (Sheoran \& Panchal, 2015).

Apabila belum ada sedikitpun perbaikan setelah melakukan upaya di rumah baik dengan pemanasan, latihan maupun obat-obatan selama lebih kurang 3 bulan, dianjurkan untuk konsultasi dengan ahlinya secara langsung. Tujuan penelitian ini adalah untuk mempelajari pengaruh metode massage eflurasi terhadap penurunan intensitas nyeri dismenorea pada mahasiswa Prodi DIII Kebidanan STIKes Hafshawaty Pesantren Zainul Hasan Probolinggo.

\section{METODE PENELITIAN}

Penelitian ini merupakan penelitian pra eksperimental (one group pretest-posttes design) dengan dilakukan pengukuran variable tergantung dari satu kelompok subjek (pretest). Subjek diberi perlakuan untuk jangka waktu tertentu dan dilakukan pengukuran kedua (posttest) terhadap variabel bebas dan hasil pengukuran pretest dibandingkan dengan hasil pengukuran posttest.

Populasi penelitian ini adalah semua mahasiswa Program Studi DIII Kebidanan STIKes Hafshawaty Pesantren Zainul Hasan Probolinggo dengan nyeri dismenorea sebesar 30 orang. Teknik sampling yang digunakan adalah total sampling sehingga sampel dalam penelitian ini sebesar 30 orang. Variabel independen dalam penelitian ini adalah pemberian terapi massage eflurasi sedangkan variabel dependen adalah intensitas nyeri.

Pengumpulan data dilakukan dengan mengukur skala nyeri yang dirasakan saat dismenore dengan menggunakan skala nyeri NRS serta kuesioner. Responden memilih salah satu angka pada skala nyeri dengan cara dilingkari sesuai dengan nyeri yang dirasakan. Analisis data untuk dismenorea dikatakan tidak mengalami nyeri dengan skor $=0$, nyeri ringan dengan skor $=1-3$ nyeri sedang dengan skor $=$ 
4-6 nyeri berat dengan skor $=7-10$, dinilai melalui skala numerik penilaian nyeri (NRS). Menganalisis hubungan antara variabel independen (pemberian terapi massage eflurasi) dengan variabel dependen (intensitas nyeri). Penelitian ini menggunakan Uji t (paired t test) untuk mengetahui perbandingan intensitas penurunan nyeri dismenorea pada mahasiswa sebelum dan sesudah diberikan massage eflurasi.

\section{HASIL DAN PEMBAHASAN}

Berikut disajikan data distribusi frekuensi responden berdasarkan usia, intensitas nyeri sebelum dan sesudah message eflurasi serta pengaruh massage eflurasi terhadap penurunan intensitas nyeri dismenorea.

Tabel 1. Distribusi Frekuensi berdasarkan Usia Mahasiswa yang Mengalami Nyeri Disminorea di Prodi DIII Kebidanan STIKes Hafshawaty Pesantren Zainul Hasan Probolinggo

\begin{tabular}{cccc}
\hline No. & $\begin{array}{c}\text { Usia } \\
(\text { tahun) }\end{array}$ & Frekuensi & $\begin{array}{c}\text { Persentase } \\
(\boldsymbol{\%})\end{array}$ \\
\hline 1 & $\leq 20$ & 18 & 60 \\
2 & $21-25$ & 12 & 40 \\
\hline & Total & 30 & 100 \\
\hline
\end{tabular}

Diperoleh hasil sebagian besar responden mahasiswa yang mengalami nyeri dismenorea berusia $\leq 20$ tahun dengan persentase $60 \%$.
Tabel 2. Distribusi Frekuensi berdasarkan Intensitas Nyeri Dismenorea sebelum Massage Eflurasi Mahasiswa di Prodi DIII Kebidanan STIKes Hafshawaty Pesantren Zainul Hasan Probolinggo

\begin{tabular}{cccc}
\hline No. & $\begin{array}{c}\text { Intensitas } \\
\text { Nyeri }\end{array}$ & $\begin{array}{c}\text { Sebelum } \\
\text { Massage } \\
\text { Eflurasi }\end{array}$ & $\begin{array}{c}\text { Persentase } \\
(\%)\end{array}$ \\
\hline 1. & Ringan & 12 & 40 \\
2. & Sedang & 16 & 53 \\
3. & Berat & 2 & 7 \\
\hline & Total & 30 & 100 \\
\hline
\end{tabular}

Diperoleh hasil sebagian besar responden sebelum dilakukan massage eflurasi mempunyai Intensitas nyeri dismenorea sedang dengan persentase $53 \%$.

Tabel 3. Distribusi Frekuensi berdasarkan Intensitas Nyeri Dismenoreaa sesudah Massage Efflurasi Mahasiswa di Prodi DIII Kebidanan STIKes Hafshawaty Pesantren Zainul Hasan Probolinggo

\begin{tabular}{cccc}
\hline No & $\begin{array}{c}\text { Intensitas } \\
\text { Nyeri }\end{array}$ & $\begin{array}{c}\text { Sesudah } \\
\text { Massage } \\
\text { Eflurasi }\end{array}$ & $\begin{array}{c}\text { Persentase } \\
(\%)\end{array}$ \\
\hline 1 & Ringan & 24 & 80 \\
2 & Sedang & 5 & 17 \\
3 & Berat & 1 & 3 \\
\hline & Total & 30 & 100 \\
\hline
\end{tabular}

Diperoleh hasil sebagian besar responden setelah dilakukan Massage Eflurasi responden mengalami nyeri dismenorea sebanyak $80 \%$.

Tabel 4. Pengaruh Massage Eflurasi terhadap Penurunan Intensitas Nyeri Dismenorea di Prodi DIII Kebidanan STIKES Hafshawaty Pesantren Zainul Hasan Probolinggo

\begin{tabular}{cccccc}
\hline No & Intensitas Nyeri & $\begin{array}{c}\text { Sebelum } \\
\text { Massage } \\
\text { Efflurasi }\end{array}$ & Persentase(\%) & $\begin{array}{c}\text { Sesudah } \\
\text { Massage } \\
\text { Efflurasi }\end{array}$ & Persentase (\%) \\
\hline 1 & Ringan & 12 & 40 & 24 & 80 \\
2 & Sedang & 16 & 53 & 5 & 17 \\
3 & Berat & 2 & 7 & 1 & 3 \\
\hline & Total & 30 & 100 & 30 & 100 \\
\hline
\end{tabular}

Berdasarkan tabel 4 diperoleh hasil setelah dilakukan massage eflurasi intensitas nyeri tertinggi adalah ringan sebanyak 24 dari total 30 responden. Berdasarkan uji statistik Uji $\mathrm{t}$ (paired $t$ test) diperoleh bahwa $p=0,00$ yang berarti kurang dari
0,05 sehingga $\mathrm{H}_{0}$ ditolak dan $\mathrm{H}_{1}$ diterima. Dengan demikian ada pengaruh penurunan intensitas nyeri dismenorea setelah dilakukan massage eflurasi, pada mahasiswa Prodi DIII Kebidanan STIKes Hafshawaty Pesantren Zainul Hasan Probolinggo. 


\section{Nyeri Dismenorea}

Berdasarkan Tabel 2 diperoleh hasil sebagian besar responden sebelum dilakukan Massage eflurasi mempunyai intensitas nyeri dismenorea sedang dengan persentase $53 \%$.

Dismenorea mulai terjadi ketika seorang remaja perempuan mencapai siklus ovulatori, pada umumnya terjadi pada 3 tahun setelah menarche (Marzouk et al., 2013).

Perbedaan intensitas nyeri dismenorea yang dirasakan oleh setiap responden dapat disebabkan oleh perbedaan waktu dimulainya menstruasi dan perbedaan persepsi terhadap nyeri yang dialami. Pengalaman nyeri seseorang dipengaruhi oleh beberapa faktor yang kemudian dapat meningkatkan atau menurunkan persepsi nyeri tersebut, diantaranya: toleransi ataupun respon individu terhadap nyeri yakni pengalaman nyeri terdahulu, budaya, kecemasan, jenis kelamin, usia dan harapan terhadap upaya penghilang nyeri (Smeltzer, 2014).

Penyebab rasa sakit pada saat menstruasi (dismenorea) belum diketahui penyebabnya sampai sekarang tetapi ada teori yang menyebutkan kekejangan pada otot rahim yang menyebabkan aliran darah tidak lancar. Sekitar 50\% wanita pernah mengeluh sakit waktu menstruasi pada masa remaja, gangguan ini bisa mencapai puncaknya pada umur sekitar usia 17-25 tahun. Hal ini sesuai dengan penelitian (Sophia, F., Muda, S., 2013) diperoleh hasil bahwa mayoritas responden remaja putri yang mengalami dismenorea berusia antara 15-17 tahun yaitu sebanyak 142 responden dari total 171 responden remaja putri yang mengalami dismenorea atau dengan persentase $83 \%$.

\section{Pengaruh metode Massage Eflurasi terhadap penurunan Intensitas Nyeri Dismenorea}

Berdasarkan hasil penelitian diperoleh informasi bahwa terdapat pengaruh massage eflurasi terhadap penurunan intensitas nyeri dismenorea.

Tindakan penanganan merupakan cara yang dilakukan seseorang dalam mengatasi suatu masalah atau penyakit yang dideritanya. Ada beberapa cara untuk mengantisipasi atau mengurangi sakit pada saat menstruasi diantaranya adalah dengan cara massage eflurasi. Massage menggunakan kedua tangan pada punggung dengan kedua tangan dengan tekanan lebih halus dan melakukan gerakan keatas untuk membantu memperlancar aliran balik vena.
Sejalan dengan penelitian (Setiawan \& Lestari, 2018) yang menyatakan bahwa metode sederhana yang dapat digunakan untuk mengurangi intensitas nyeri secara alami yaitu dengan melakukan massage pada area yang tepat. Massage adalah alternatif pilihan yang tepat alamiah dan sederhana yang dengan cepat dapat mengurangi rasa nyeri selain memakai obat-obatan. Massage dengan kedua tangan pada punggung, menggunakan teknik gerakan ke atas untuk membantu aliran balik vena, massage eflurasi adalah rangsangan secara kutaneus berupa usapan yang mengalir dengan lembut. Dengan massage eflurasi hipoksia pada jaringan akan berkurang sehingga kadar oksigen di jaringan meningkat yang menyebabkan nyeri berkurang. Selain itu, massage eflurasi dapat meningkatkan pelepasan hormon endorfin sehingga ambang nyeri menurun (Apay et al., 2012).

Sejalan dengan penelitian (Amin, M, Purnamasari, 2020) bahwa adanya pengaruh pemberian terapi massage eflurasi terhadap penurunan skala nyeri dismenorea primer dikarenakan terapi Massage Eflurasi yang diberikan membuat relaksasi otot abdomen sehingga sangat efektif untuk menurunkan rasa nyeri dismenorea primer.

Sejalan dengan penelitian (Astri, 2021) Berdasarkan hasil penelitian menunjukkan bahwa sebagian besar sampel penelitian merasakan adanya penurunan skala nyeri dismenorea setelah pemberian terapi counterpressure.

Sesuai dengan penelitian lain yang dilakukan oleh (Mortazavi et al., 2012) untuk menilai efek terapi pijat dan kehadiran petugas pada tingkat rasa sakit, kecemasan dan kepuasan selama persalinan. Kelompok pijat telah menurunkan intensitas nyeri pada fase kedua dan ketiga dibandingkan dengan kelompok petugas.

Apabila sudah dilakukan upaya seperti minum obat-obatan ataupun latihan dan masih belum ada perbaikan kurang labih 3 bulan dan tidak menunjukkan perbaikan sedikitpun maka diperlukan konsultasi dengan dokter.

\section{KESIMPULAN DAN SARAN}

Dari penelitian yang telah dilakukan dapat disimpulkan bahwa terdapat pengaruh massage eflurasi terhadap penurunan intensitas nyeri dismenorea. Untuk penelitian selanjutnya disarankan untuk melakukan massage eflurasi pada area yang tepat. 


\section{REFERENSI}

Amin, M, Purnamasari, Y. (2020). Penurunan Skala Nyeri Dismenorea Primer Pada Remaja Putri Menggunakan Massage Effleurage. Journal of Telenursing (JOTING), 2, 142149.

Apay, S. E., Arslan, S., Akpinar, R. B., \& Celebioglu, A. (2012). Effect of Aromatherapy Massage on Dysmenorrhea in Turkish Students. Pain Management Nursing, 13(4), 236-240. https://doi.org/10.1016/j.pmn.2010.04.002

Astri, Y. (2021). Jurnal Bidan Komunitas. Jurnal Bidan Komunitas, 4(1), 45-52. http://ejournal.helvetia.ac.id/index.php/jbk

Hestiantoro A. (2012). Masalah Gangguan Haid dan Infertilitas. FKUI, Jakarta.

Kusmiran, E. (2011). Kesehatan Reproduksi Remaja Dan Wanita. Salemba Medika.

Marzouk, T. M. F., El-Nemer, A. M. R., \& Baraka, H. N. (2013). The effect of aromatherapy abdominal Massage on alleviating menstrual pain in nursing students: A prospective randomized cross-over study. Evidence-Based Complementary and Alternative Medicine, 2013. https://doi.org/10.1155/2013/742421

Mortazavi, S. H., Khaki, S., Moradi, R., Heidari, K., \& Vasegh Rahimparvar, S. F. (2012). Effects of Massage therapy and presence of attendant on pain, anxiety and satisfaction during labor. Archives of Gynecology and Obstetrics, 286(1), 19-23.https://doi.org/10.1007/s00404-012-2227-4
Nirwana AB. (2011). No TitlPsikologi Kesehatan Wanita (Remaja Menstruasi, Menikah, Hamil, Nifas, Menyusui)e. Nuha Medika.

Prawirohardjo, S. (2011). Ilmu Kebidanan. Yayasan Bina Pustaka Sarwono.

Prayitno S. (2014). Buku Lengkap Kesehatan Organ Reproduksi Wanita. Jakarta: Saufa.

Setiawan, S. A., \& Lestari, L. (2018). Hubungan Nyeri Haid (Dismenorea) dengan Aktivitas Belajar Sehari-Hari Pada Remaja Putri Kelas VII Di SMPN 3 Pulung. 9(8), 24-31.

Sheoran, P., \& Panchal, R. (2015). A Study to Assess the Effectiveness of Abdominal Effleurage on Labor Pain Intensity and Labour Outcomes Among Nullipara Mothers During 1 st Stage of Labor In Selected Hospitals of District. Journal of Caring Sciences, 4(1), 1585-1590.

Smeltzer, S. (2014). Buku Keperawatan Medical Bedah Edisi 12. EGC, Jakarta.

Sophia, F., Muda, S., J. (2013). Faktor-Faktor Yang Berhubungan Dengan Dismenorea Pada Siswi SMK Neger 10 Medan. Tugas Akhir.

Trisnowiyoto, B. (2012). Keterampilan Dasar Massage, Panduan Keterampilan Dasar Pijat Bagi Fisioterapis, Praktisi, dan Instruktur. Nuha Medika. 